\title{
MARKET STRUCTURE AND COMPETITION AMONG RETAIL DEPOSITORY INSTITUTIONS
}

\author{
Andrew Cohen* \\ Federal Reserve Board of Governors \\ and \\ Michael Mazzeo \\ Kellogg School of Management \\ Northwestern University
}

December 2003

\begin{abstract}
We assess the competitive impact that single-market banks and thrift institutions have on multi-market banks (and vice-versa) in 1,884 nonMSA markets. We estimate a model of equilibrium market structure which endogenizes entry for three types: multi-market banks, single-market banks, and thrift institutions. Observed market structures and the solution to an entry-type game identify the parameters of a latent (unobserved) profit function. We find significant evidence of product differentiation - particularly in the case of thrifts. Furthermore, product differentiation appears to depend upon differences in market geography.
\end{abstract}

JEL classification: L11, L13, G21, G28

*The views expressed in this paper are those of the authors and do not necessarily reflect the view of the Board of Governors or its staff. We are grateful to Robin Prager for useful comments. 


\section{INTRODUCTION}

The U.S. banking industry has seen dramatic changes over the past several years. Liberalization of bank branching restrictions and the ability of bank holding companies to operate nationwide have lead to significant consolidation in the retail banking industry during the late 1990s. The U.S. banking market has become increasingly dominated by large banking organizations operating in numerous local markets across wide geographic areas. Smaller "single-market" banks and thrift institutions (savings banks and savings and loans) are, therefore, an important potential source of competition for large "multi-market" banking institutions in the local markets in which they operate. We attempt to assess the competitive impact that single-market banks and thrift institutions have on multi-market banks (as well as each other) in 1,884 non-MSA markets.

A recent development in the Industrial Organization literature [see Sutton (1991) and Bresnahan and Reiss (1990 and 1991)] has been to recognize that observed industry structure provides information about firm profitability ${ }^{1}$ from which, in turn, inferences can be made about the nature of competition. In particular, the entry decisions of potential competitors and the continued market participation of extant firms depend on several factors including: (1) fixed costs; (2) the nature of post-entry competition; and (3) the entry/operating decisions of other firms. By assuming that each incumbent firm earns positive profits, and that opportunities for additional firms to enter the market were not taken because they were not profitable, we can deduce the competitive effect of additional market participants. Extending this intuition to account for heterogeneity in firm type allows us to estimate and contrast the extent to which the presence of similar and differentiated firms affect profits. We estimate such a model of endogenous market structure for three types of depository institutions: multi-market banks, singlemarket banks, and thrifts.

We find evidence of significant differentiation between multi-market banks, singlemarket banks, and thrifts. In order to explore the rule of market geography on differentiation, the sample was split between the more and less rural of our markets (based on 
proximity to MSAs). Our results can be summarized as follows:: (1) competition is significantly more stringent between firms of the same type than between firms of differing types; (2) thrifts appear to be only moderate substitutes for both types of banks, though they are much better substitutes in less rural markets; (3) multi-market banks are more competitive (and face stiffer competition from single-market banks) in more rural markets; and (4) single market banks face stiffer competition from multimarket banks (and thrifts) in less rural markets.

The remainder of the paper is organized as follows. Section II provides background on issues of market definition in banking antitrust and discusses the previous literature on the geographic expansion of banking markets and the role of non-bank financial institutions. Section III presents a model of endogenous market structure for depository institutions and discusses its estimation. Section IV presents the empirical results and Section V concludes.

\section{BACKGROUND AND SIGNIFICANCE}

Our study focuses on two important questions in bank antitrust analysis: (1) What effect has expanding geographic coverage by large banking institutions had on competition in local markets?; and, (2) To what extent are thrift institutions substitutes for banks? Both of these questions were debated in Congress preceding the passage of the GrammLeach-Bliley Act of 1999. Rep. Rick Lazio of New York addressed concerns about consolidation in the banking industry by appealing to small banks and thrifts as potential substitutes for larger banking organizations during Congressional hearings in 1998, "We have over 9,000 banks right now. That number will certainly drift down... But at the same time, the main street bank, the smaller thrift, will continue to thrive in their niche..." In addition to the public policy questions, ascertaining the extent to which thrift institutions are substitutes for banks is an important question for regulators. At present, the four regulatory bodies with oversight of bank mergers have three different rules of thumb (discussed below) for treating thrift institutions in merger analysis. 
In general, inference about the exercise of market power in the banking industry is especially difficult. Banks offer a wide variety of products (e.g., consumer loans, small business loans, checking accounts, and savings accounts) for which comprehensive price and quantity data are rarely available at disaggregate (product/geographic market specific) levels. ${ }^{2}$ Banks in a particular geographic market may compete closely in some products, while not in others. The Supreme Court has interpreted antitrust laws based on the idea that the banks provide a "cluster" of services that are assumed to be traded in local markets. ${ }^{3}$ An advantage of our model is that it allows for analysis of competition between multi-market banks, single-market banks and thrifts in terms of the cluster of services they provide, rather than along individual product lines.

While banking organizations have grown in size and geographic scope, there is strong evidence that banking markets are local in nature. Studies using data from the Federal Reserve's the Survey of Consumer Finances and the National Survey of Small Business Finances [Elliehausen and Wolken (1990 and 1992), Kwast, Starr-McCluer and Wolken (1997) and Amel and Starr-McCluer (2002)] have found that (1) consumers and small businesses tend to obtain their bank services from nearby providers, and (2) consumers tend to obtain multiple financial services from the same bank. ${ }^{4}$ Also, numerous studies have found a relationship between local market concentration and deposit or loan interest rates. Radecki (1998) documents the practice whereby multimarket banks offer the same interest rate in different MSAs and interprets this as evidence that banking markets are not local in nature. Heitfield (1999), however, shows that single-market bank interest rates differ substantially across MSAs suggesting that local market conditions dictate the pricing behavior of single-market banks.

The role of thrift institutions adds another dimension to competition in retail banking markets. Thrifts play an important role in bank merger analysis as they are considered to be a potential source of competition for banks. In the past, thrifts had been treated differently than banks because they traditionally had not offered the same product lines. In fact, the Supreme Court found in 1974 that thrifts competed in a different product market than commercial banks because they did not offer the same cluster of services. ${ }^{5}$ The relaxation of statutory restrictions that had prevented thrift institutions from offering demand deposit accounts and engaging in commercial and industrial (C\&I) 
lending have greatly reduced many of the practical differences between banks and thrifts. ${ }^{6}$ The issue of whether (or to what extent) to include thrifts as market competitors has not been resolved by the relevant antitrust authorities. These agencies construct Herfindahl-Hirschman Index (HHI) screens using deposit market share as a proxy for the degree of competition over the entire cluster of services offered by banks. ${ }^{7}$ The Office of the Comptroller of the Currency and the FDIC include 100\% of thrift deposits in computing bank HHIs, while the Federal Reserve Board typically includes $50 \%$ of thrift deposits, and the Depatment of Justice includes either 100\% of thrift deposits or none at all (depending on the extent to which the thrift is involved in C\&I lending).

Some recent papers have begun to explore how these different types of depository institutions might compete with each other. For example, Hannan and Prager (forthcoming) find that local market concentration is negatively related to deposit rates offered by single-market banks, but that the effect attenuates as the share of deposits at multi-market banks increases. Biehl (2002), using data from five metropolitan areas in New York state, shows that single-market banks offer higher interest rates on deposits than multi-market banks and that those rates are positively correlated with rates offered by other single-market banks in the area, while multi-market banks' deposit rates are not correlated with rates offered by other banks in the area. This work may be somewhat limited to the extent that exhaustive data from a large number of markets are not available. These findings suggest that multi-market banks operate in fundamentally different ways than single-market banks and that multi-market banks may engage in softer competition than single-market banks. Adams, Brevoort and Kiser (2003) structurally estimate demand and measure product differentiation among single-market banks, multimarket banks, and thrifts, but focus on only a single product (deposit accounts) that these institutions offer. Finally, Amel and Hannan (2000) estimate residual deposit supply equations for two bank products, MMDAs and NOW accounts. They find very small elasticities of the residual bank supply curve and interpret this as suggesting that only banks, should be included in the "market" used in bank merger analysis. $^{8}$

Cohen (2003) comes the closest to our approach. That paper estimates two sets of entry models for banks and thrifts. In the first model, banks and thrifts are treated as if they 
were a no different from one another. In the second model, banks and thrifts are treated as if they have no competitive interaction with one another. A test of the two models soundly rejects the latter in favor of the former. While the test is able to say that it is more likely that banks and thrifts are identical in their competitive effects rather than being totally unrelated, it is unable to handle any intermediate cases. Quantifying the strength of substitution between banks (in this case both single and multi-market) and thrifts, therefore, is an extension of Cohen (2003).

Our approach to analyzing competition between multi-market banks, single-market banks and thrift institutions is novel in several respects. We estimate a model of equilibrium market structure that specifies distinct behavioral functions for each of the three types, with which we can identify variables that increase the probability of entry for each type of firm. In addition, the model allows us to explicitly measure the extent to which the existence of competitors may decrease profitability - and to compare the competitive effects across types. For example, we are able to distinguish between the extent to which a single-market bank degrades the profits of a multi-market bank and the effect that a single-market bank has on the profits of other single-market banks. We use this comparison to arrive at a measure of differentiation between the two types of institutions. Estimating the model requires only data on the observed set of firms operating in a cross section of geographic markets. We, therefore, do not need to rely on price or quantity data, which are very difficult to obtain at the appropriate level of disaggregation. Furthermore, our results can be interpreted as speaking to the substitutability of the cluster of services offered by multi-market banks, single-market banks and thrifts, consistent with the standards for bank antitrust analysis laid out in U.S. v. Philadelphia National Bank. ${ }^{9}$

\section{A MODEL OF ENDOGENOUS MARKET STRUCTURE IN LOCAL BANKING MARKETS}

The empirical analyses in this paper are designed to examine the competitive consequences of concentrated industry structure in local banking markets. Because of the difficulty in obtaining accurate and comparable data on traditional competition 
metrics, we make use of the so-called "multiple-agent qualitative-response" models that are employed in the industrial organization literature to evaluate entry strategies and market competition. ${ }^{10}$ In these models, firms' strategies can be represented by discrete decisions (e.g., enter/don't enter a particular market) that are arrived at by evaluating the profitability of the potential alternatives. The goal of the econometrician is to estimate parameters of the profit functions using information provided by the firms' observed decisions. For example, we infer that a firm is profitable based on its presence in the market and that an additional market participant would not be profitable. Estimation in this context is complicated by the fact that the decisions of competing firms likely affect the profitability of the potential alternatives - for example, operating may be less profitable to the extent that competitors are also present in the market. A game theoretic behavioral model is therefore used to infer individual firm profitability from an observed market structure outcome, determined by the choices made by interacting agents. Because our goal is to assess the competitiveness of different types of depository institutions, we analyze a model where each distinct type of institution has a separate behavioral function.

The inspiration for our analytical framework comes from Bresnahan and Reiss (1991). They propose a simple yet flexible profit function that governs behavior in a symmetric equilibrium in market $m$. The profit of each operating firm is given by:

$$
\Pi_{m}=(\text { Variable Profits })_{m} *(\text { Market Size })_{m}-(\text { Entry Costs })_{m} .
$$

Note that the effects of competition are incorporated by allowing variable profits to be a function of the number of firms. Specifically, let the profits of each of $n$ symmetric firms operating in market $m$ equal:

$$
\Pi_{n, m}=X_{m} \beta-\mu_{n}+\varepsilon_{m}
$$

where $X_{m}$ are exogenous market factors (including market size), $\mu_{n}$ measures the effect of $n$ competitors on per-firm profits, and $\varepsilon_{m}$ is a market-level error term assumed to follow a normal distribution. We assume that firms enter the market if they earn nonnegative profits. Therefore, the probability of observing $n$ firms in equilibrium equals:

$$
P\left(\Pi_{n} \geq 0 \text { and } \Pi_{n+1}<0\right)=\Phi\left(\bar{\Pi}_{n}\right)-\Phi\left(\bar{\Pi}_{n+1}\right)
$$


where $\Phi$ is the cumulative normal density function and $\bar{\Pi}_{n}=X_{m} \beta-\mu_{n}$. Bresnahan and Reiss used an ordered probit model to estimate the $\beta$ and $\mu_{n}$ parameters.

To accommodate differentiation among competitors, we follow Mazzeo (2002) and employ a model that endogenizes product type choice as well as entry. We identify competitors as being one of three types of depository institution (either "multi-market" bank, "single-market" bank, or "thrift") and posit a separate profit function for competitors of each type. This allows us to determine whether same-type competitors affect profits more than different-type competitors. We include both the number and product types of competitors as arguments in the reduced-form profit function. We treat all firms within a given profit type as symmetric.

Given these assumptions, we can specify the profits of a firm of type $T$ in market $m$, where market m contains $N_{1}$ firms of type $1, N_{2}$ firms of type 2 and $N_{3}$ firms of type $3: 11$

$$
\pi_{T, m, N_{1}, N_{2}, N_{3}}=X_{m} \beta_{T}+g\left(\theta_{T} ; \overrightarrow{N_{1}}, \overrightarrow{N_{2}}, \overrightarrow{N_{3}}\right)+\varepsilon_{T m}
$$

The first term represents market demand characteristics that affect firm profits (note that the effect of $X_{m}$ is allowed to vary by type). The $g\left(\theta_{T} ; \overrightarrow{N_{1}}, \overrightarrow{N_{2}}, \overrightarrow{N_{3}}\right)$ portion of the profit function captures the effects of competitors, with the vectors $\overrightarrow{N_{1}}, \overrightarrow{N_{2}}$ and $\overrightarrow{N_{3}}$ representing the number of competing firms of each type. Parameters in the $g\left(\theta_{T} ; \overrightarrow{N_{1}}, \overrightarrow{N_{2}}, \overrightarrow{N_{3}}\right)$ function can distinguish between the effects on profits of sametype firms and the competitive effects of firms of each of the different-types. The set of $\theta$ parameters can also be specified to the capture the incremental effects of additional firms of each type. Note that the parameter vector $\theta$ varies across types, T; this allows the competitive effects to potentially differ by type. The unobserved part of profits, $\varepsilon_{\mathrm{Tm}}$, is assumed to be different for each product type in a given market.

To proceed, we need to make an assumption about the nature of the entry process. We will start by assuming that there are three possible types of depository institutions that could enter a given market — multi-market bank (M) single-market bank (S) or thrift 
(T). Abstracting from differences among firms of the same type, firms that do enter market $m$ earn $\pi_{T m}\left(\overrightarrow{N_{1}}, \overrightarrow{N_{2}}, \overrightarrow{N_{3}}\right)$, where $T$ is the product type of the firm and $\overrightarrow{N_{1}}, \overrightarrow{N_{2}}, \overrightarrow{N_{3}}$ represents the number and product types of all the competitors that also operate in market $m .{ }^{12}$ Firms that do not enter earn zero.

We estimate the model assuming that the observed outcome is arrived at as if the potential entrants were playing a Stackelberg game. In such a specification, players would sequentially make irrevocable decisions about entry before the next firm plays. As they make these entry decisions, firms anticipate that potential competitors of each type will subsequently make entry decisions once the earlier movers have committed to their choice. ${ }^{13}$ While this is clearly an abstraction, we use the Stackelberg game because it assumes that the higher profit types will enter based on a market structure in which the least profitable entrant ultimately makes profits. This is an attractive feature because it implies that the Stackelberg outcome is observationally equivalent to the outcome that would obtain in the long run of a repeated simultaneous move entry/exit game, to the extent that the later entry of a higher profit firm would likely precipitate the subsequent exit of a competitor that is no longer profitable as a result. ${ }^{14}$

For this game, a Nash Equilibrium can be represented by an ordered triple (M, S, T) for which the following inequalities are satisfied: ${ }^{15}$

$$
\begin{array}{ll}
\pi_{M}(M-1, S, T)>0 & \pi_{M}(M, S, T)<0 \\
\pi_{S}(M, S-1, T)>0 & \pi_{S}(M, S, T)<0 \\
\pi_{T}(M, S, T-1)>0 & \pi_{T}(M, S, T)<0
\end{array}
$$

and 


$$
\begin{aligned}
& \pi_{M}(M-1, S, T)>\pi_{S}(M-1, S, T) \\
& \pi_{M}(M-1, S, T)>\pi_{T}(M-1, S, T) \\
& \pi_{S}(M, S-1, T)>\pi_{M}(M, S-1, T) \\
& \pi_{S}(M, S-1, T)>\pi_{T}(M-1, S, T) \\
& \pi_{T}(M, S, T-1)>\pi_{M}(M, S, T-1) \\
& \pi_{T}(M, S, T-1)>\pi_{S}(M, S, T-1)
\end{aligned}
$$

As long as we assume that an additional market participant always decreases profits and that the decrease is larger if the market participant is of the same product type, a unique equilibrium exists. ${ }^{16}$

Under the specification described above, the inequalities corresponding to exactly one of the possible ordered-triple market structure outcomes are satisfied for every possible realization of $\left(\varepsilon_{\mathrm{M}}, \varepsilon_{\mathrm{S}}, \varepsilon_{\mathrm{T}}\right)$ based on the data for the market in question and values for the profit function parameters. Assuming a distribution for the error term, a predicted probability for each of the possible outcomes is calculated by integrating $f\left(\varepsilon_{\mathrm{M}}, \varepsilon_{\mathrm{S}}, \varepsilon_{\mathrm{T}}\right)$ over the region of the $\left\{\varepsilon_{\mathrm{M}}, \varepsilon_{\mathrm{S}}, \varepsilon_{\mathrm{T}}\right\}$ space corresponding to that outcome.

Since the equilibrium is unique, the sum of the probabilities for all market configurations always equals one. Maximum likelihood selects the profit function parameters that maximize the probability of the observed market configurations across the dataset. The likelihood function is:

$$
L=\prod_{m=1}^{M} \operatorname{Prob}\left[(M, S, T)_{m}^{O}\right]
$$

where $(M, S, T)_{m}^{O}$ is the observed configuration of firms in market $m-$ its probability is a function of the solution concept, the parameters and the data for market $m$. For example, if $(M, S, T)^{O}=(1,1,1)$ for market $m$, the contribution to the likelihood function for market $m$ is Prob $[(1,1,1)]$. Note that analytically computing the probability of each outcome is exceedingly complex in the case of three product types. 
As a result, simulation techniques are used in estimation. Appendix A describes the simulation method.

\section{RESULTS}

We estimate the three-type endogenous market structure model using data from 1,884 non-MSA labor market areas (LMAs) as of June 30, 2000. Because it is critical to control for demographic conditions, geographic markets should be defined in such a way that (1) all the firms in the geographic area actually compete with each other and (2) consumers do not typically use firms outside their own geographic area. To accomplish (1), we focus on smaller geographic markets, which are unlikely to contain distinct submarkets. We therefore eliminated all urbanized areas (MSAs) and larger rural areas (LMAs with more than 100,000 residents). The LMA definition helps us to meet the second requirement. While counties have typically been used to delineate geographic markets, such a definition would be inappropriate to the extent that political boundaries do not represent meaningful economic distinctions. The Bureau of Labor Statistics defines LMAs as integrated economic areas, based on commuting patterns between counties. Contiguous counties are combined into a single LMA if at least 15 percent of the workers from one county commute for work to the other. Using LMAs gives us more confidence that two neighboring markets are indeed competitively distinct. $^{17}$

To construct the dependent variable - the number of institutions of each of the three types within the LMA - we use data from several sources. The number of multimarket and single-market banks operating in each LMA was obtained from the FDIC summary of deposits. A bank was classified as a single-market bank (in a given market) if more than 80 percent of its deposits were received from branches in that market. Otherwise, the bank was classified as a multi-market bank. ${ }^{18}$ The number of thrifts operating in each LMA was obtained from the Office of Thrift Supervision's Branch Office Survey. Tables 1 shows the distribution of firm configurations among the LMA markets in our dataset. Each panel of the table represents a particular number of thrifts in the market, with the rows and columns of each panel referring to single-market banks 
and multimarket banks, respectively. The numbers in the table represent the number of markets in which the operating firms follow the given configuration - for example, there are 72 markets that include one multimarket bank, one single-market bank and zero thrifts.

Note that we have collapsed the distribution of markets from above for each of the three categories - that is all markets with three or more thrifts are treated as if they have exactly three, all markets with four or more single-market banks are treated as if they have exactly four, and all markets with six or more multi-market banks are treated as if they have exactly six. We expect this to reduce the complexity of the estimation without influencing the results, as other studies have found competitive effects of additional firms that die out after three or four competitors (Bresnahan \& Reiss, Mazzeo).

The following variables were included in $\mathrm{X}$, the vector of exogenous market factors that may also affect the profitability of financial institutions across the LMAs in the dataset: (1) the number of farms; (2) the number of non-farm establishments; (3) population; (4) per capita income; and, (5) the housing unit occupancy rate. These variables are intended to capture market size — the demand for services of banks and thrifts - in each market. The sources for these variables are the Agricultural Census, the Bureau of Economic Analysis, and the Census Bureau. Each X-variable was rescaled by dividing each observation by the mean of that variable. The transformed variables all have a mean of one, which aids in the estimation. Table 2 presents summary statistics for the unscaled variables. Finally, we examined potential differences among our markets by noting which of the LMAs were adjacent to MSAs. We will below compare competition among institutions in the more and less rural markets in the sample.

The reported estimates reflect the following specification of the competitive-effect dummy variables: ${ }^{19}$ 


$$
\begin{aligned}
g_{\mathrm{M}}= & \theta_{M M 1} * \text { presence of first multi-market bank competitor } \\
& +\theta_{M M 2} * \text { presence of second multi-market bank competitor } \\
& +\theta_{M M 3} * \text { number of additional multi-market bank competitors } \\
& +\theta_{M S 1} * \text { presence of first single-market bank competitor } \\
& +\theta_{M S 2} * \text { number of additional single-market bank competitors } \\
& +\theta_{M T 1} * \text { presence of first thrift competitor } \\
& +\theta_{M T 2} * \text { number of additional thrift competitors } \\
g_{\mathrm{S}}= & \theta_{S S 1} * \text { presence of first single-market bank competitor } \\
& +\theta_{S S 2} * \text { presence of second single-market bank competitor } \\
& +\theta_{S S 3} * \text { presence of third single-market bank competitor } \\
& +\theta_{S M 1} * \text { presence of first multi-market bank competitor } \\
& +\theta_{S M 2} * \text { number of additional multi-market bank competitors } \\
& +\theta_{S T 1} * \text { presence of first thrift competitor } \\
& +\theta_{S T 2} * \text { number of additional thrift competitors } \\
g_{\mathrm{T}}= & \theta_{T T 1} * \text { presence of first thrift competitor } \\
& +\theta_{T T 2} * \text { presence of second thrift competitor } \\
& +\theta_{T M 1} * \text { presence of first multi-market bank competitor } \\
& +\theta_{T M 2} * \text { number of additional multi-market bank competitors } \\
& +\theta_{T S 1} * \text { presence of first single-market competitor } \\
& +\theta_{T S 2} * \text { number of additional single-market competitors }
\end{aligned}
$$

Table 3 presents the maximum likelihood estimates from our three type endogenous market structure model. The estimated parameters indicate the relative payoffs for each type of institution under different market conditions and in different competitive situations. For example, consider monopolists (all $\theta$ parameters multiplied by zero) operating in markets with sample mean values for all of the X-variables (all $\beta$ parameters multiplied by one). In this scenario, a multi-market bank would expect to earn 2.97, while a single-market bank would expect to earn 1.15, and a thrift would expect to earn $.02 .^{20}$ These figures represent predicted payoffs, and are normalized based on the standard normal assumption of the market-specific unobservables. We can use the estimates, therefore, to compare the relative profitability of the various types and to check whether operating at all is profitable - if predicted payoffs are positive. 
The estimated coefficients on the $\mathrm{X}$-variables are (with one exception) positive, reflecting that more institutions of each type are likely to operate when these market size proxies are positive. ${ }^{21}$ Differences in the estimated $\beta$ parameters across types reflect how these various measures might stimulate one type of institution more than another. Single-market banks, for example, do relatively better than multi-market banks and thrifts in markets with more farms suggesting that single-market banks have a comparative advantage in more agrarian environments. In contrast, multi-market banks do better in markets with more business establishments.

In our sample, the probability that a multi-market bank monopolist would earn higher profits than a single-market bank monopolist is $86.8 \%$, while the probability that a multi-market bank monopolist would earn higher profits than a thrift monopolist is $97.1 \%$, and the probability that a single-market bank monopolist would earn higher profits than a thrift monopolist is $77.9 \%$. This suggests that multi-market banks may be more efficient than single-market banks (and thrifts). While there may be several causes including economies of scale, better access to external (non-deposit) sources of funding, and greater ability to diversity loan portfolios, our analysis is not able to separate these effects.

The top panel of table 3 presents the parameters $\left(\theta_{T}\right)$ that capture the amount that the presence of particular competitors reduce payoffs for each type of institution. For example, the estimated $\theta_{\mathrm{MM} 1}$ equals -1.10 ; therefore, the estimated payoff to a multimarket bank in a "sample mean" market where the only competition is another multimarket bank is $(2.97-1.10)=1.87$. Within type competition appears to be tightest for thrifts $\left(\theta_{\mathrm{TT} 1}\right.$ equals -1.19$)$ and lowest for single market banks $\left(\theta_{\mathrm{SS} 1}\right.$ equals $\left.\quad-0.93\right)$. In all cases, the incremental effect of additional same-type competitors decreases as the number of same-type competitors increases. This is consistent with the predictions of a several standard pricing games. ${ }^{22}$

We are particularly interested in the cross-type effects measuring how firms of one type affect the profits of other-type firms. Crucially, in all cases the effects of same-type competitors are greater than different-type institutions. If the multi-market bank's 
competitor in the previous example were a single market bank, payoffs would be higher: $2.97-0.54=2.43$ (vs. 1.87). This reflects substantial product differentiation among the three types of financial institutions in the rural markets in our dataset. Looking across the types, multi-market banks and single market banks appear to affect each other more than thrifts affect either. We can measure differentiation by comparing the estimated $\theta$-parameters; for example, the first single-market bank has about half of (-.55) the effect of the first multi-market bank (-1.10) on multi-market banks. Interestingly, while the first thrift competitor has almost no competitive effect on multimarket (or single-market) bank profits, additional thrifts reduce multi-market bank profits by about a third (-0.27 vs. -0.75$)$ as much additional multi-market bank competitors. It is possible that intense competition between thrifts (when there is more than one) results in outcomes that attract consumers away from banks. There also may be differences across markets - markets that are relatively more attractive to thrifts (that is, markets with larger and wealthier populations) may also be those markets where thrifts are viewed by consumers as good substitutes for banks. This view suggests that the substitutability of banks and thrifts may depend upon market characteristics in more complex ways than our specification can capture.

As discussed previously, each type prefers to face a competitor of a different type. We nonetheless observe configurations involving multiple firms of the same type, which can be explained by the interaction of the demand shifters (the $\beta^{\prime} s$ ) and the competitive effects (the $\theta^{\prime} s$ ). For example, in Baker County Florida the number of farms, establishments and per-capita income are all below the sample mean, while the population is right around the sample mean and the occupancy rate is above the sample mean (see table 4). Each of the three extant multi-market banks would expect to earn profits of .21. There are no single-market banks (who would expect to earn losses of .02 ) or thrifts (who would expect to earn losses of .49). Each of the multi-market banks would prefer to face one fewer multi-market bank and an additional single-market bank or thrift. We do not observe either of these configurations, however, because neither a single-market bank (with expected profits of .09) nor a thrift (with expected losses almost unchanged at .47) could exist in an equilibrium with two multi-market banks. (A 
single-market bank would do better as a multi-market bank, thereby enticing predatory entry by a third multi-market bank forcing the single-market bank to subsequently exit.)

\section{Border Markets vs. Rural Markets}

An important assumption of our empirical model is that the markets in our sample are comparable in the sense that the map from the $\mathrm{X}$-variables to equilibrium firm configurations is the same across markets. While we tried to select smaller non-MSA markets to insure that there were no systematic differences across the geographic markets, we explored potential differences relating to market geography by splitting our sample in two. We defined markets as either "rural" or "border." LMAs were considered rural if they did not share a border with an MSA; if they did share a border with an MSA, they were placed in the border market category. Our sample consists of 829 rural markets and 1,055 border markets. We re-estimated the model on each subsample. Tables $3 \mathrm{~A}$ and $3 \mathrm{~B}$ present the results for the rural and border markets, respectively.

The likelihood ratio statistic testing the null hypothesis that the two sets of markets are equivalent is constructed by subtracting the log likelihood for the original model from the sum of the log likelihoods for the two subsamples, and then multiplying by two. The statistic is 44.73 . With 38 degrees of freedom, we are unable to reject the null hypothesis that the two subsamples are equivalent at the $20 \%$ level of significance, which gives us some confidence that our two subsamples are sufficiently similar to one another. It is nonetheless informative to examine the differences in some of the estimated coefficients.

Multi-market banks appear to compete more stringently with one another in rural markets than in the border markets. They are also more affected by competition from single-market banks in rural markets. Single market banks, however, are more affected by competition from multi-market banks in the border markets. Given that competition among single-market banks is comparable in the two types of markets, and that multimarket banks compete more stringently in rural markets, we cannot infer that the reduced effect of multi-market banks on single-market bank profits is entirely due to 
differences in the intensity of competition. The estimates suggest that single-market banks have relatively more market power and that multi-market banks have relatively less market power due to product differentiation (either vertical or horizontal) in rural markets.

Thrifts appear to be closer substitutes for both types of banks in the border markets. Thrift profits are unaffected by the presence of either type of bank in rural markets. In border markets, however, the first multi-market competitor reduces thrifts profits by $27 \%$ as much as the first thrift competitor, and the first single-market competitor reduces thrift profits by $22 \%$ as much as the first thrift competitor. The coefficient describing the effect of the first thrift on multi-market bank profits is much larger for the border markets, though the effect of subsequent thrift entrants is somewhat less. Both the effect of the first and subsequent thrift entrants on single-market bank profits are significantly larger in the border markets. ${ }^{23}$ Further support for the idea that thrifts are viewed differently in rural and border markets is the fact that a thrift monopolist would expect to earn significantly greater profits in a border market (.39 vs. a loss of .06 in a rural market) with the $\mathrm{X}$-variables set to the sample mean.

\section{CONCLUSION}

Using a model of endogenous market structure, we are able to quantify the effects of differentiation between multi-market banks, single-market banks, and thrifts on competition among retail depository institutions. Our results suggest that differentiation between the three types of institution is significant. By splitting our sample into rural markets and markets bordering MSAs, we find evidence that the nature of product differentiation may depend on the type of market under consideration.

We find evidence of modest substitution between thrifts and multi-market banks (and to a lesser extent, single-market banks). While thrifts are functionally quite similar to banks, banks and thrifts look as though they are reasonably different. This is a somewhat surprising finding, but our results actually suggest more substitution between 
thrifts and banks than has been found in the previous literature. The fact that thrifts may be regarded quite differently by consumers in different markets is an interesting possibility suggested by our results. If this is the case, then the practice of determining whether thrift institutions are substitutes for a merging bank may be best handled on a case-by-case basis.

An important caveat to this work is that we have abstracted from the effect of credit unions. Credit unions are significantly smaller in scale than both banks and thrifts. Nonetheless, they have been shown to be somewhat competitive with banks along certain product lines. We would also like to consider this in future work.

\section{APPENDIX}

Let $\Pi_{\mathrm{T}}$ represent the non-stochastic portion of the profit function, $\pi_{\mathrm{T}}$, that corresponds to each type T. The likelihood for a given market (the market subscript is omitted) is defined as the probability that the following sets of inequalities hold.

$$
\begin{aligned}
& -\Pi_{M}(M-1, S, T)<\varepsilon_{M}<-\Pi_{M}(M, S, T) \\
& -\Pi_{S}(M, S-1, T)<\varepsilon_{S}<-\Pi_{S}(M, S, T) \\
& -\Pi_{T}(M, S, T-1)<\varepsilon_{T}<-\Pi_{T}(M, S, T)
\end{aligned}
$$

and,

$$
\begin{aligned}
& \Pi_{M}(M-1, S, T)+\varepsilon_{M}>\max \left[\Pi_{S}^{*}(M-1, S, T)+\varepsilon_{S}, \Pi_{T}^{*}(M-1, S, T)+\varepsilon_{T}\right] \\
& \Pi_{S}(M, S-1, T)+\varepsilon_{S}>\max \left[\Pi_{M}^{*}(M, S-1, T)+\varepsilon_{S}, \Pi_{T}^{*}(M, S-1, T)+\varepsilon_{T}\right] \\
& \Pi_{T}(M, S, T-1)+\varepsilon_{T}>\max \left[\Pi_{M}^{*}(M, S, T-1)+\varepsilon_{S}, \Pi_{S}^{*}(M, S, T-1)+\varepsilon_{T}\right]
\end{aligned}
$$

where $\Pi_{S}{ }^{*}(M-1, S, T)$ is $\Pi_{S}(M-1, S, T)$ if the configuration $\{M-1, S+1, T\}$ satisfies the condition that all firms make positive profits and no firm could profitably enter (as any type), otherwise, $\Pi_{\mathrm{S}}{ }^{*}(\mathrm{M}-1, \mathrm{~S}, \mathrm{~T})=-\varepsilon_{\mathrm{S}} . \Pi_{\mathrm{M}}{ }^{*}$ and $\Pi_{\mathrm{T}}{ }^{*}$ are defined analogously.

Using the law of iterated expectations, we can rewrite the likelihood for a given market as:

$\operatorname{Pr}(\mathbf{1}$ and $\mathbf{2}$ are true $)=\operatorname{Pr}(\mathbf{2}$ is true $\mid \mathbf{1}$ is true $) * \operatorname{Pr}(\mathbf{1}$ is true $)$ 
We assume that the type-specific errors are independent from one another. This allows us to compute the first set of inequalities analytically. Then we simulate the probability that the second set of inequalities hold, given that the first set hold. Our simulator for the likelihood is obtained by following the procedure outlined below.

1. Take three sets of independent draws, $\{\mathrm{u}, \mathrm{v}, \mathrm{w}\}$, from a uniform $(0,1)$ distribution. For each evaluation of the objective function, repeat steps 2 through 5 to obtain the likelihood simulator.

2. Calculate analytically $P_{1}=\operatorname{Pr}\left[\begin{array}{l}-\Pi_{M}(M-1, S, T)<\varepsilon_{M}<-\Pi_{M}(M, S, T), \\ -\Pi_{S}(M, S-1, T)<\varepsilon_{S}<-\Pi_{S}(M, S, T), \\ -\Pi_{T}(M, S, T-1)<\varepsilon_{T}<-\Pi_{T}(M, S, T)\end{array}\right]$

3. Invert each set of draws $\left\{\mathrm{u}_{\mathrm{d}}, \mathrm{v}_{\mathrm{d}}, \mathrm{w}_{\mathrm{d}}\right\}$ to obtain a set of normal draws $\left\{\mathrm{e}_{\mathrm{M}, \mathrm{d}}, \mathrm{e}_{\mathrm{S}, \mathrm{d}}, \mathrm{e}_{\mathrm{T}, \mathrm{d}}\right\}$ truncated at $-\Pi_{\mathrm{M}}(\mathrm{M}-1, \mathrm{~S}, \mathrm{~T})$ and $-\Pi_{\mathrm{M}}(\mathrm{M}, \mathrm{S}, \mathrm{T}) ;-\Pi_{\mathrm{S}}(\mathrm{M}, \mathrm{S}-1, \mathrm{~T})$ and $-\Pi_{\mathrm{S}}(\mathrm{M}, \mathrm{S}, \mathrm{T})$; and $-\Pi_{\mathrm{T}}(\mathrm{M}, \mathrm{S}, \mathrm{T}-1)$ and $-\Pi_{\mathrm{T}}(\mathrm{M}, \mathrm{S}, \mathrm{T})$, respectively.

4. Calculate the following indicator for each of the truncated draws:

$$
I_{d}=I\left(\begin{array}{l}
\Pi_{M}(M-1, S, T)+e_{M, d}>\max \left[\Pi_{S}^{*}(M-1, S, T)+e_{S, d}, \Pi_{T}^{*}(M-1, S, T)+e_{T, d}\right] \\
\Pi_{S}(M, S-1, T)+e_{S, d}>\max \left[\Pi_{M}^{*}(M, S-1, T)+e_{M, d}, \Pi_{T}^{*}(M, S-1, T)+e_{T, d}\right] \\
\Pi_{T}(M, S, T-1)+e_{T, d}>\max \left[\Pi_{M}^{*}(M, S, T-1)+e_{S, d}, \Pi_{S}^{*}(M, S, T-1)+e_{T, d}\right]
\end{array}\right)
$$

5. Take the average of the indicator function over the draws to construct a frequency simulator of the conditional probability.

$$
\widetilde{\mathrm{P}}_{2 \mid 1}=\frac{1}{\mathrm{D}} \sum_{\mathrm{d}=1}^{\mathrm{D}} \mathrm{I}_{\mathrm{d}}
$$

6. Calculate the simulated likelihood as $\widetilde{\mathrm{L}}=\mathrm{P}_{1} * \widetilde{\mathrm{P}}_{2 \mid 1}$

Our approach has several advantages. First, it reduces simulation error relative to a traditional frequency estimator because part of the likelihood is computed analytically. 
As a result, all of the draws that are taken are useful in determining whether the configuration has the property that no type would do better as a different type. The traditional approach would take a set of draws from the full range of the unobservables, and any draws for which the first set of inequalities failed to hold, would provide no useful information about the second set of inequalities. Now, each draw provides useful information about the second set of inequalities.

Another advantage of our approach is that it is smoother than a simple frequency simulator. Frequency simulators present two related problems in estimation. The objective function will have flat spots and jumps. That is, there will be regions where the parameters change without a corresponding change in the objective function, and when the objective function does change, it does so discontinuously. Because we calculate the probability of the first set of inequalities analytically, our objective function always changes with a change in the parameters. Using the frequency simulator outlined in steps 4 and 5 above, however, our objective function will still have discontinuities. We attempt to fix this problem by smoothing the indicator function described in step 4 . We calculate instead,

$$
\widetilde{I}_{d}=\left[\begin{array}{l}
\Phi\left(\frac{\Pi_{M}(M-1, S, T)+e_{M, d}-\max \left[\Pi_{S}^{*}(M-1, S, T)+e_{S, d}, \Pi_{T}^{*}(M-1, S, T)+e_{T, d}\right]}{\delta}\right) * \\
\Phi\left(\frac{\Pi_{S}(M, S-1, T)+e_{S, d}>\max \left[\Pi_{M}^{*}(M, S-1, T)+e_{M, d}, \Pi_{T}^{*}(M, S-1, T)+e_{T, d}\right]}{\delta}\right) * \\
\Phi\left(\frac{\Pi_{T}(M, S, T-1)+e_{T, d}>\max \left[\Pi_{M}^{*}(M, S, T-1)+e_{S, d}, \Pi_{S}^{*}(M, S, T-1)+e_{T, d}\right]}{\delta}\right)
\end{array}\right]
$$

where $\Phi$ is the standard normal CDF and $\delta$ is a bandwidth parameter that goes to zero as $\mathrm{N}$ goes to infinity. We then calcuate $\widetilde{\mathrm{P}}_{2 \mid 1}=\frac{1}{\mathrm{D}} \sum_{\mathrm{d}=1}^{\mathrm{D}} \widetilde{\mathrm{I}}_{\mathrm{d}}$ and proceed as before. This smoothing technique has been used in Berry (1992) and Mazzeo (2002). 


\section{$\underline{\text { REFERENCES }}$}

Adams, R., Brevoort K. and Kiser E., "Who Competes with Whom? The Case of Depository Institutions," Federal Reserve Board, working paper.

Amel, Dean, and Timothy Hannan, "Defining Banking Markets According to the Principles Recommended in the Merger Guidelines," The Antitrust Bulletin 45 (Fall 2000) pp. 615-639.

Amel, D. and Starr-McCluer, M. "Market Definition in Banking: Recent Evidence," The Antitrust Bulletin 47 (Spring 2002) pp. 63-88.

Andrews, D. and Berry, S. "On Placing Bounds on Parameters of Entry Games in the Presence of Multiple Equilibria," Mimeo (2002), Yale University.

Berry, S. "Estimation of a Model of Entry in the Airline Industry," Econometrica 60 (July 1992) pp. 889-917.

Biehl, A. "The Extent of the Market for Retail Banking Deposits," The Antitrust Bulletin, 47 (Spring 2002) pp. 91-106.

Bresnahan T. and Reiss P. "Entry in Monopoly Markets." Review of Economic Studies 57 (October 1990) pp. 531-553.

Bresnahan T. and Reiss P. "Entry in Concentrated Markets," Journal of Political Economy, 99 (October 1991) pp. 977-1009.

Ciliberto, F. and Tamer, E. "Market Structure and Multiple Equilibria in Airline Markets," Mimeo (2003).

Cohen, A. "Market Structure and Market Definition: The Case of Small Banks and Thrifts," Mimeo, Federal Reserve Board. 
"Eliminating the Thrift Charter," CBO Paper, (June 1997).

Elliehausen, G. and Wolken J. "Banking Markets and the Use of Financial Services by Households," Federal Reserve Bulletin 78 (March 1992) pp. 169-181.

Elliehausen, G. and Wolken J. "Banking Markets and the Use of Financial Services by Small and Medium Sized Businesses," Federal Reserve Bulletin 76 (October 1990) pp. 801-817.

Feinberg, R. "The Competitive Role of Credit Unions in Small Local Financial Markets," The Review of Economics and Statistics 83 (August 2001) pp. 560-563.

Hannan, T. and Prager, R. "The Competitive Implications of Multimarket Bank Branching," Journal of Financial Services Research, forthcoming.

Heitfield, E. "What Do Interest Rate Data Say About the Geography of Retail Banking Markets?” Antitrust Bulletin 44 (Summer 1999) pp. 333-347.

Kwast, M., Starr-McCluer, M. and Wolken, J. "Market Definition and the Analysis of Antitrust in Banking," Antitrust Bulletin 42 (Winter 1997) pp. 973-995.

Mazzeo, M. "Product Choice and Oligopoly Market Structure," RAND Journal of Economics, 33 (Summer 2002) pp. 1-22.

Pakes, A., “Common Sense and Simplicity in Industrial Organization,” mimeo (2003).

Radecki, L. "The Expanding Geographic Reach of Retail Banking Markets," Federal Reserve Bank of New York Economic Policy Review (June 1998) pp. 15-33.

Reiss, P. "Empirical Models of Discrete Strategic Choices," American Economic Review, 86 (1996) pp. 421-426. 
Seim, K. "An Emprical Model of Entry with Endogenous Product-Type Choices," mimeo, (2003).

Sutton, J. Sunk Costs and Market Structure, MIT Press, Cambridge, (1991).

Tamer, E. "Incomplete Simultaneous Discrete Response Model with Multiple Equilibria," Review of Economic Studies, 70, (2003) pp. 147-167.

Toivanen, O. and Waterson, M. "Market Structure and Entry: Where's the Beef?," mimeo (1999).

Tokle R. and Tokle J. "The Influence of Credit Union and Savings and Loan Competition on Bank Deposit Rates in Idaho and Montana," Review of Industrial Organization 17 (December 2000) pp. 427-439.

U.S. v. Connecticut National Bank, 418 U.S. 656, 94 S.Ct. 2788, 41 L.Ed.2d. 1016 (1974).

U.S. v. Philadelphia National Bank, 374 U.S. 321, 83 S.Ct. 1715.10 L.Ed.2d. 915 (1963).

${ }^{1}$ In particular, market structure provides information about economic profits which are not directly observed.

2 There are several papers studying competition in banking markets that use price data. Some papers have used survey data, which are often for a particular product in a limited geographic area. Others have used constructed prices which tend to be aggregated over different products and geographic areas.

${ }^{3}$ United States v. Philadelphia National Bank, (1963).

${ }^{4}$ This finding supports the idea of banks providing a cluster of services.

${ }^{5}$ United States v. Connecticut National Bank, (1974). 
6 While it is true that thrifts are able to offer a wider variety of products, it is not clear that they actually have availed themselves of these options. Pilloff and Prager (1998), for example, find that thrift C\&I lending was limited despite the removal of some of the restrictions on it.

${ }^{7}$ Bank mergers receive closer scrutiny if the post-merger HHI increases by more than 200 to a level above 1800 in any market involved in the merger.

${ }^{8}$ Credit Unions are another potentially important competitor that other researchers have studied in a similar way. For example, Tokle and Tokle (2000) find that local market shares for credit union deposits are associated with higher interest rates on bank CDs in Idaho and Montana, and Feinberg (2001) finds that larger credit union deposit shares are associated with lower bank lending rates on unsecured and new vehicle loans. As discussed below, it may be possible to extend the type of analysis we do here to include credit unions, given the availability of appropriate data.

${ }^{9}$ Our results do not speak to whether or not the "cluster", as proscribed in United States v. Philadelphia National Bank, is the correct standard for bank antitrust analysis. Rather, the analysis is conducted in a manner that is consistent with the idea of the cluster.

${ }^{10}$ In addition to the papers cited here, see Berry (1992), Toivanen and Waterson (1999) and Seim (2000). Reiss (1996) provides a discussion of the empirical framework.

${ }^{11}$ This specification of the profit function was chosen primarily to make the estimation tractable. Following Berry (1992) and Bresnahan and Reiss (1991), it can be interpreted as the log of a demand (market size) term multiplied by a variable profits term that depends on the number (and product types, in this case) of market competitors. There are no firm-specific factors in the profit function. The error term 
represents unobserved payoffs from operating as a particular type in a given market. It is assumed to be additively separable, independent of the observables (including the number of market competitors), and identical for each firm of the same type in a given market.

12 We assume that firms optimize on a market-by-market basis, which may be somewhat less realistic for multi-market banks (it is conceivable that such a bank might enter an individual market to broaden its coverage, even if that market is not individually profitable). By not analyzing the larger markets that would be more attractive for this purpose, difficulties caused by this difference should be mitigated.

13 A natural alternative is a simultaneous move game; however, it has been well established that such a game has multiple equilibria, which precludes straightforward econometric estimation (Bresnahan \& Reiss, Tamer). New methodologies that are currently being developed to estimate in the presence of multiple equilibria (e.g., Berry \& Andrews, Ciliberto \& Tamer) remain beyond the scope of this paper. We proceed with the Stackelberg assumption, in part relying on the finding in Mazzeo (2002) that parameter estimates are very similar across various game formulations that generate unique equilibria.

${ }^{14}$ Long-run, dynamic equilibrium models of entry and exit have been proposed, but have not yet been successfully estimated. See Pakes (2003) for a discussion of recent progress in this area.

${ }^{15}$ Recall that $\pi_{M}(M, S, T)$ corresponds to the profits of a multi-market bank under the configuration $(\mathrm{M}+1, \mathrm{~S}, \mathrm{~T})$ since a multi-market firm faces $\mathrm{M}$ multi-market bank competitors, S single-market bank competitors, and T thrift competitors. 
${ }^{16}$ Mazzeo (2002) contains proofs of existence and uniqueness. Note that $\vec{N}$ represents the product types of competing firms (not including itself). For example, for a multimarket bank in market (M,S, T), $\vec{N}=(\mathrm{M}-1, \mathrm{~S}, \mathrm{~T})$; for a thrift, $\vec{N}=(\mathrm{M}, \mathrm{S}, \mathrm{T}-1)$.

17 In addition, these markets have far fewer competitors, making the model more tractable. More importantly, many of the mergers that raise competitive concerns with regulators do so because of their effect on smaller markets.

${ }^{18}$ This definition is consistent with previous papers that distinguish "single-market" banks. Note that a bank with 90 percent of its deposits in market $\mathrm{A}$ and 10 percent in market B would, according to this definition, be classified as a single-market bank in market $\mathrm{A}$ and a multimarket bank in market $\mathrm{B}$. This reflects the view that the decision to operate in market B would be significantly more affected by the role of the branch in B in the bank's overall network, as opposed to in market A where the presence of any branches in market B would be less important.

${ }^{19}$ The goal is to make the specification of the competitive effects through $g\left(\theta_{T} ; \vec{N}\right)$ as flexible as possible, while maintaining estimation feasibility. For example, in the cases where the data indicate the "number" of competitors, we implicitly assume that the incremental effect of each additional competitor is the same.

${ }^{20}$ For example, for the multi-market monopolist, predicted payoffs $=(-1.10+0.56+$ $1.09+0.13+0.70+1.59)=2.97$.

${ }^{21}$ The one exception is the effect of population on single-market bank profits, which is estimated to be negative. This may suggest that single-market banks have a harder time servicing large populations or, alternatively, are associated with more personalized service in smaller markets. 
${ }^{22}$ Such games include a Cournot game with homogenous goods, see Bresnahan and Reiss (1991), or a Bertrand pricing game with symmetric product differentiation.

${ }^{23}$ We should note, however, that all of the cross-type effects involving thrifts are estimated imprecisely in the border subsample All but one of the cross-type effects are estimated imprecisely in the total sample as well as the rural subsample. 
Table 1: Market Configurations

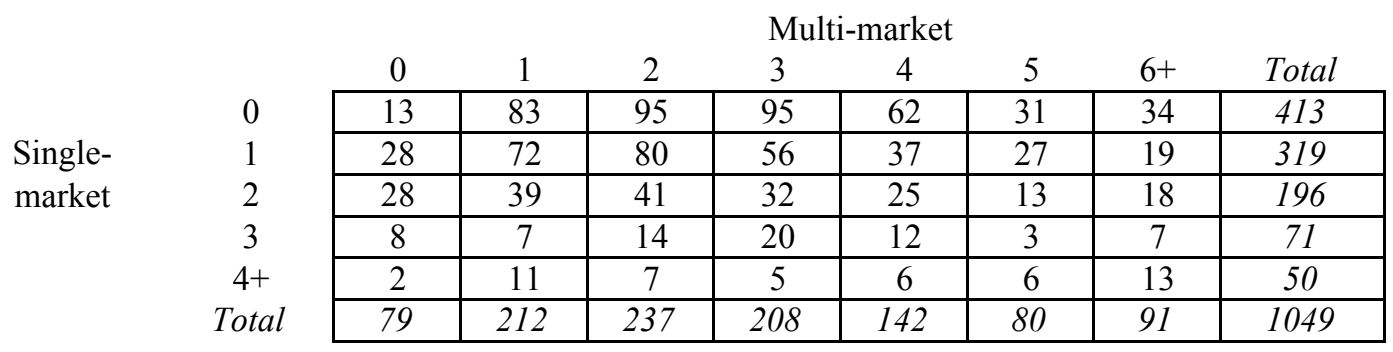

Thrifts $=0$

\begin{tabular}{|c|c|c|c|c|c|c|c|c|c|}
\hline \multirow{7}{*}{$\begin{array}{l}\text { Single- } \\
\text { market }\end{array}$} & \multirow{7}{*}{$\begin{array}{c}0 \\
1 \\
2 \\
3 \\
4+ \\
\text { Total }\end{array}$} & 0 & 1 & 2 & 3 & 4 & 5 & $6+$ & Total \\
\hline & & 4 & 9 & 22 & 40 & 34 & 30 & 29 & 168 \\
\hline & & 5 & 28 & 24 & 32 & 24 & 18 & 34 & 165 \\
\hline & & 10 & 10 & 16 & 25 & 12 & 14 & 19 & 106 \\
\hline & & 1 & 8 & 9 & 9 & 15 & 8 & 16 & 66 \\
\hline & & 3 & 5 & 12 & 8 & 16 & 13 & 18 & 75 \\
\hline & & 23 & 60 & 83 & 114 & 101 & 83 & 116 & 580 \\
\hline
\end{tabular}

Thrifts $=1$

Multi-market

Single-

0

\begin{tabular}{|c|c|c|c|c|c|c|c|}
\multicolumn{1}{c}{0} & 1 & 2 & 3 & 4 & 5 & $6+$ & Total \\
\hline 0 & 5 & 9 & 10 & 6 & 9 & 15 & 54 \\
\hline 1 & 2 & 4 & 10 & 10 & 11 & 14 & 52 \\
\hline 1 & 2 & 6 & 8 & 3 & 5 & 12 & 37 \\
\hline 0 & 1 & 1 & 5 & 2 & 3 & 9 & 21 \\
\hline 1 & 0 & 1 & 5 & 5 & 2 & 7 & 21 \\
\hline 3 & 10 & 21 & 38 & 26 & 30 & 57 & 185 \\
\hline
\end{tabular}

Thrifts $=2$

market

1
2
3
$4+$
Total

Multi-market

Singlemarket

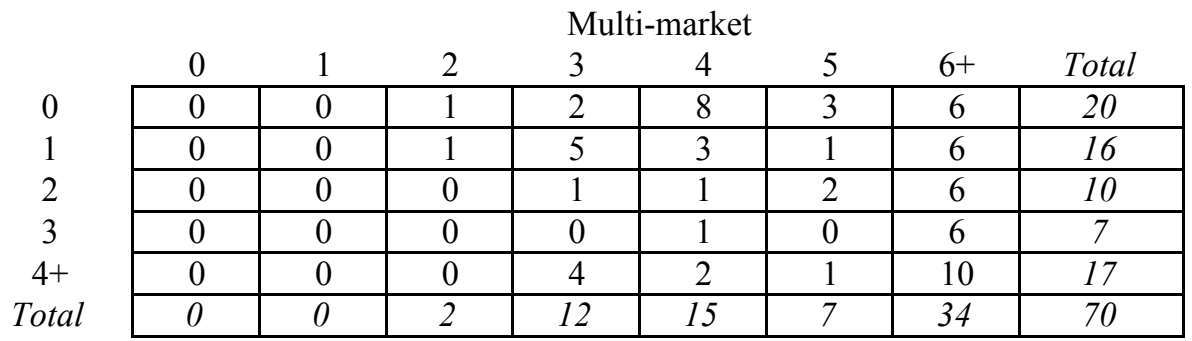

Thrifts $=3+$ 
Table 2: Market Size Variables

Variable
Population
Per Capita Income
Farms
Establishements
Occupancy Rate

$\mathrm{N}=1,884$

Transformation Used: $\mathrm{X}^{*}=\mathrm{X} /(\Sigma \mathrm{X} / \mathrm{N})$

$\begin{array}{cccc}\text { Mean } & \text { Std. Dev. } & \text { Min } & \text { Max } \\ 23,299 & 19,944 & 65 & 99,428 \\ 20,943 & 3,980 & 5,475 & 69,960 \\ 617 & 452 & 0 & 4,302 \\ 542 & 508 & 1 & 4,855 \\ 0.83 & 0.10 & 0.23 & 0.97 \\ & & & \end{array}$


Table 3: Parameter Estimates from Endogenous Market Structure Model

COMPETITIVE EFFECTS

Effect of first multi-market competitor on multi-market profits

Effect of second multi-market competitor on multi-market profits

Effect of each additional multi-market competitor on multi-market profits

Effect of first single-market on multi-market profits

Effect of each additional single-market on multi-market profits

Effect of first thrift on multi-market profits

Effect of each additional thrift on multi-market profits

Effect of first single-market competitor on single-market profits

Effect of second single-market competitor on single-market profits

Effect of third single-market competitor on single-market profits

Effect of first multi-market on single-market profits

Effect of each additional multi-market on single-market profits

Effect of first thrift on single-market profits

Effect of each additional thrift on single-market profits

Effect of first thrift competitor on thrift profits

Effect of second thrift competitor on thrift profits

Effect of first multi-market on thrift profits

Effect of each additional multi-market on thrift profits

Effect of first single-market on thrift profits

Effect of each additional single-market on thrift profits
Estimate Std Error

$-1.0970 \quad 0.0646$

$-0.8193 \quad 0.0387$

$-0.7452 \quad 0.0195$

$-0.5453 \quad 0.1037$

$-0.1103 \quad 0.0513$

$-0.0329 \quad 0.1345$

$-0.2745 \quad 0.0920$

$-0.9291 \quad 0.0357$

$-0.7228 \quad 0.0346$

$-0.5552 \quad 0.0375$

$-0.3696 \quad 0.1706$

$-0.1098 \quad 0.0513$

-7.E-06 0.1665

$-0.1388 \quad 0.1596$

$-1.1889 \quad 0.0464$

$-0.8918 \quad 0.0627$

$-0.0309 \quad 0.1768$

$-0.0149 \quad 0.0691$

$-0.1214 \quad 0.1633$

$-0.0004 \quad 0.1031$

$-1.1031$

0.2721

$0.5621 \quad 0.0568$

$\begin{array}{ll}1.0887 & 0.0748\end{array}$

$0.1258 \quad 0.0801$

$0.7045 \quad 0.1443$

$\begin{array}{ll}1.5923 & 0.2609\end{array}$

Per Capita Income

Occupancy Rate
$-2.2107$

0.7099

0.4843

$-0.3261$

0.5118

1.9770

Per Capita Income

Occupancy Rate
0.3328

0.0570

0.1032

0.0922

0.2205

0.3057

THRIFT PROFIT SHIFTERS

Intercept

$-2.0512$

0.3262

Farms

0.2901

0.0957

Establishments

0.3871

0.0950

Population

$0.1618 \quad 0.0936$

Per Capita Income

$0.8546 \quad 0.1842$

Occupancy Rate

$0.3763 \quad 0.3482$

$\mathrm{N}=1884$

Log Likelihood $=-7192.63$ 
Table 3A: Parameter Estimates from Endogenous Market Structure Model Rural Markets

COMPETITIVE EFFECTS

Effect of first multi-market competitor on multi-market profits

Estimate

Std Error

Effect of second multi-market competitor on multi-market profits

$-1.1770 \quad 0.0762$

Effect of each additional multi-market competitor on multi-market profits

$-0.8625 \quad 0.0548$

Effect of first single-market on multi-market profits

$\begin{array}{ll}-0.7689 & 0.0309\end{array}$

Effect of each additional single-market on multi-market profits

$-0.5666 \quad 0.1210$

Effect of first thrift on multi-market profits

$-0.1317 \quad 0.0623$

Effect of each additional thrift on multi-market profits

$-0.0019 \quad 0.1469$

$-0.3204 \quad 0.1268$

Effect of first single-market competitor on single-market profits

$\begin{array}{ll}-0.9429 & 0.0436\end{array}$

Effect of second single-market competitor on single-market profits

$-0.7294 \quad 0.0447$

Effect of third single-market competitor on single-market profits

$-0.6030 \quad 0.0634$

Effect of first multi-market on single-market profits

$-0.3366 \quad 0.1948$

Effect of each additional multi-market on single-market profits

$-0.1177$

0.0424

Effect of first thrift on single-market profits

$-0.0003$

0.1582

Effect of each additional thrift on single-market profits

$-0.0748$

0.1329

Effect of first thrift competitor on thrift profits

$\begin{array}{ll}-1.2665 & 0.0744\end{array}$

Effect of second thrift competitor on thrift profits

$-0.7848 \quad 0.1050$

Effect of first multi-market on thrift profits

$-0.0020 \quad 0.2459$

Effect of each additional multi-market on thrift profits

$-0.0096 \quad 0.0785$

Effect of first single-market on thrift profits

$-0.0087 \quad 0.1649$

Effect of each additional single-market on thrift profits

-1.E-14 0.1018

MULTI-MARKET PROFIT SHIFTERS

Intercept

$-1.2407$

0.3954

Farms

$0.7568 \quad 0.0845$

Establishments

0.9699

0.1392

Population

0.3147

0.1620

Per Capita Income

0.6799

0.2195

Occupancy Rate

1.6243

0.3617

SINGLE-MARKET PROFIT SHIFTERS

Intercept

$-2.6047$

0.4205

Farms

0.7133

0.0527

Establishments

0.3703

0.1420

Population

$-0.1363$

0.1740

Per Capita Income

0.8166

0.2533

Occupancy Rate

2.0300

0.3975

THRIFT PROFIT SHIFTERS

Intercept

$-2.1350$

0.4488

Farms

0.3104

0.1092

Establishments

0.4964

0.1064

Population

0.0320

0.1521

Per Capita Income

0.7411

0.2962

Occupancy Rate

$0.4918 \quad 0.4190$

$\mathrm{N}=829$

Log Likelihood $=-3084.1$ 
Table 3B: Parameter Estimates from Endogenous Market Structure Model Border Markets

COMPETITIVE EFFECTS

Effect of first multi-market competitor on multi-market profits

Effect of second multi-market competitor on multi-market profits

Effect of each additional multi-market competitor on multi-market profits

Effect of first single-market on multi-market profits

Effect of each additional single-market on multi-market profits

Effect of first thrift on multi-market profits

Estimate Std Error

Effect of each additional thrift on multi-market profits

$-1.0191 \quad 0.0976$

$-0.7956 \quad 0.0569$

$-0.7375 \quad 0.0286$

$-0.5376 \quad 0.1666$

$-0.0511 \quad 0.0861$

$-0.0818 \quad 0.2019$

$-0.2250 \quad 0.1402$

Effect of first single-market competitor on single-market profits

$-0.9258$

0.0490

Effect of second single-market competitor on single-market profits

$-0.7252$

0.0479

Effect of third single-market competitor on single-market profits

$-0.5286$

0.0483

Effect of first multi-market on single-market profits

$-0.4299$

0.2922

Effect of each additional multi-market on single-market profits

$-0.1429$

0.0890

Effect of first thrift on single-market profits

$-0.0609$

0.3897

Effect of each additional thrift on single-market profits

$-0.1600$

0.2912

Effect of first thrift competitor on thrift profits

$-1.1540$

0.0653

Effect of second thrift competitor on thrift profits

$-0.9623$

0.0850

Effect of first multi-market on thrift profits

$-0.3094$

0.2564

Effect of each additional multi-market on thrift profits

$-0.0315$

0.1026

Effect of first single-market on thrift profits

$-0.2591$

0.3198

Effect of each additional single-market on thrift profits

$-0.0232$

0.2094

MULTI-MARKET PROFIT SHIFTERS

Intercept

$-1.1503$

0.4168

Farms

0.4311

0.0859

Establishments

1.0870

0.1103

Population

0.0745

0.1103

Per Capita Income

0.9947

0.2577

Occupancy Rate

1.4790

0.4119

SINGLE-MARKET PROFIT SHIFTERS

Intercept

$-2.3485$

0.5201

Farms

0.7226

0.0970

Establishments

0.5788

0.1550

Population

$-0.3785$

0.1414

Per Capita Income

0.4000

0.3730

Occupancy Rate

$2.3106 \quad 0.4450$

THRIFT PROFIT SHIFTERS

Intercept

$-1.9369$

0.5641

Farms

0.3187

0.1700

Establishments

0.2674

0.1839

Population

$0.3154 \quad 0.1599$

Per Capita Income

$1.0220 \quad 0.2494$

Occupancy Rate

$0.4031 \quad 0.6510$

$\mathrm{N}=829$

Log Likelihood $=-3084.1$ 
Table 4: Baker County Florida Example

Demographic Variables

Population

$\underline{\text { Baker }} \underline{\text { Sample }}$

County Mean

Per Capita Income

$22,388 \quad 23,299$

Farms

$19,056 \quad 20,943$

Establishements

$157 \quad 617$

Occupancy Rate

$278 \quad 542$

$0.93 \quad 0.83$

Observed Configuration $\quad(\mathrm{M}, \mathrm{S}, \mathrm{T})=(3,0,0)$

\section{Expected Profits at Relevant Configurations}

\begin{tabular}{|c|c|c|c|}
\hline Configuration & $\mathrm{E}\left(\Pi_{\mathrm{M}}\right)$ & $\mathrm{E}\left(\Pi_{S}\right)$ & $\mathrm{E}\left(\Pi_{\mathrm{T}}\right)$ \\
\hline$(3,0,0)$ & 0.21 & 0 & 0 \\
\hline$(3,1,0)$ & -0.34 & -0.02 & 0 \\
\hline$(3,0,1)$ & 0.18 & 0 & -0.49 \\
\hline$(2,1,0)$ & 0.41 & 0.09 & 0 \\
\hline$(2,0,1)$ & 0.92 & 0 & -0.47 \\
\hline
\end{tabular}

